\title{
EDITORIAL
}

\section{Thyroid Surgery: Whose Domain Is It?}

\author{
Peter Zbären · Jatin P. Shah • Gregory W. Randolph • Carl E. Silver • \\ Kerry D. Olsen · Ashok R. Shaha · Mark Zafereo · Luiz P. Kowalski • \\ Carlos Suarez · Alvaro Sanabria • Vincent Vander Poorten (D) · \\ Iain Nixon · Alessandra Rinaldo $\cdot$ Alfio Ferlito
}

Received: July 17, 2019 / Published online: August 10, 2019

(C) The Author(s) 2019

\section{ABSTRACT}

In the United States of America (US), most departments of otorhinolaryngology head and neck surgery have been performing thyroid surgery for many years. In contrast to the US, thyroid surgery is still dominated by general surgeons in most European countries. In numerous university centers, there continues to be friction regarding thyroid surgery. The focus

Enhanced Digital Features To view enhanced digital features for this article go to https://doi.org/10.6084/ m9.figshare.9165323.

P. Zbären $(\bowtie)$

Department of Otorhinolaryngology, Head and Neck Surgery, University Hospital, Bern, Switzerland e-mail: peter.zbaeren@insel.ch

J. P. Shah · A. R. Shaha

Head and Neck Service, Memorial Sloan-Kettering

Cancer Center, New York, NY, USA

G. W. Randolph

Division of Thyroid and Parathyroid Endocrine

Surgery, Department of Otolaryngology,

Massachusetts Eye and Ear Infirmary, Boston, MA, USA

C. E. Silver

Department of Surgery, University of Arizona

College of Medicine, Phoenix, AZ, USA

K. D. Olsen

Department of Otorhinolaryngology, Mayo Clinic, Rochester, MN, USA of this editorial is to demonstrate that there is objective data in the literature to suggest that otorhinolaryngologists with appropriate training in head and neck surgery are well suited to perform the entire spectrum of thyroid surgery. The question of who is qualified to perform thyroid surgery is not determined by the basic specialty certification of the surgeon-general or otolaryngology; rather it depends on the training, skill and experience in surgery of the neck, of post-surgical and post-irradiated necks, and of neighboring structures.

\section{Zafereo}

Head and Neck Surgery, MD Anderson Cancer Center, Houston, TX, USA

\section{P. Kowalski}

Department of Head and Neck Surgery and Otorhinolaryngology, A.C. Camargo Cancer Center, São Paulo, Brazil

C. Suarez

Instituto de Investigación, Sanitaria del Principado de Asturias, Ovideo, Spain

C. Suarez

Instituto Universitario de Oncologia del Principado de Asturias, Universidad de Ovideo, Oviedo, Spain

A. Sanabria

Department of Surgery, School of Medicine, Universidad de Antioquia, Fundación Colombiana de Cancerología-Clínica Vida, Medellin, Colombia 
Keywords: General surgery; Head and neck surgery; Otorhinolaryngology; Qualification; Thyroid surgery; Training

\section{INTRODUCTION}

Head and neck surgery in general, and thyroid surgery in particular, were developed and performed by general surgeons from the onset of the modern era of surgery, starting in the late nineteenth and until the mid-twentieth century. Around the period of World War II, otolaryngologists began to perform oncologic surgery in the neck, the upper aerodigestive tract and, eventually, the thyroid gland.

In the United States of America (US), most departments of otolaryngology head and neck surgery have been performing thyroid surgery for many years. In 2000, J.K. Harness, MD, a surgeon from Oakland, California, stated, in his presidential address on the occasion of the 21st annual meeting of the American Association of Endocrine Surgeons: "The field of endocrine surgery is no longer the sole turf of general surgeons: ear, nose and throat specialists are increasingly performing thyroid and parathyroid operations" [1]. Sixteen years later, Ashok R. Shaha, a head and neck surgeon from a general surgery background stated in the "2016 Hayes Martin Lecture" at the American Head and Neck Society's Ninth International Conference: "Endocrine surgery now accounts for a bulk of surgical procedures in the head and neck surgeon's practice" [2]. In the US, thyroid and parathyroid gland surgery is now performed by a group of

\section{Vander Poorten}

Department of Oncology-Section Head and Neck Oncology, Otorhinolaryngology-Head and Neck Surgery and Leuven Cancer Institute, University Hospitals Leuven, KU Leuven, Leuven, Belgium

\section{Nixon}

Ear, Nose and Throat Department, NHS Lothian, University of Edinburgh, Edinburgh, UK

\section{A. Rinaldo}

University of Udine School of Medicine, Udine, Italy

\section{A. Ferlito}

International Head and Neck Scientific Group, Padua, Italy surgeons, including those with a general training background and those with otolaryngology training. Many articles dealing with thyroid surgery or guidelines on the management of thyroid pathologies have been written jointly by endocrine surgeons with a general surgery background, head and neck surgeons from either an otolaryngology or a general surgery background, and endocrinologists [3-8]. In 2006, the World Congress on Thyroid Cancer was conceived by Jatin P. Shah, a head and neck surgeon with a general surgery background, and eventually founded as an organization with the aim to bring together all specialties involved in the care of patients with thyroid nodules and thyroid cancer. The steering committee of this organization is composed of five head and neck surgeons (two with a general surgery background and three with an otorhinolaryngology background), two endocrinologists, and one medical oncologist $[9,10]$.

In contrast to the US, thyroid surgery in many European countries is still dominated by general surgeons. In numerous university centers globally, there continues to be friction regarding who is qualified to perform thyroid surgery.

The focus of this editorial is to demonstrate that there are objective data in the literature to suggest that, with adequate training and the scope of practice similar to general surgeons, otolaryngologists with appropriate training in head and neck surgery are well suited to perform the entire spectrum of thyroid and parathyroid surgery.

\section{Compliance with Ethics Guidelines}

This article is based on previously conducted studies and does not contain any studies with human participants or animals performed by any of the authors.

\section{HISTORICAL DEVELOPMENT OF SURGICAL SPECIALTIES AND THYROID SURGERY}

Specializations in surgery began in the nineteenth century; the first specialties to emerge 
were ophthalmology and otorhinolaryngology [11]. During the first half of the twentieth century, surgical specialty training became more standardized and several certifying boards of specialty training developed outside general surgery, such as American Boards of Urology, Neurological Surgery, Thoracic Surgery, etc. [12]. After World War II, many surgical specialties acquired departmental status outside of general surgery.

In the US, head and neck surgery as a specialty was organized by the Society of Head and Neck Surgeons, founded in 1954 by Hayes Martin a general surgeon, and the American Society of Head and Neck Surgery, founded in 1958 by John Conley, an otolaryngologist. In the former, the members consisted mainly of general surgeons with a special training in surgical oncology and head and neck surgery, and, in the latter, of otolaryngologists with special interest and training in head and neck surgery. In 1998, these two societies merged, as their goals, aims and missions were the same [13].

Thyroid surgery was developed in the second half of the nineteenth century by Billroth (1829-1894) in Vienna and Theodor Kocher (1841-1917) in Bern, and in the first half of the twentieth century by William S. Halsted (1852-1922) at Johns Hopkins Hospital in Baltimore, Charles Mayo (1863-1939) in Rochester, George W. Crile (1864-1943) in Cleveland, and Frank H. Lahey (1880-1953) in Boston [14, 15]. Theodor Kocher received the Nobel Prize in Medicine and Physiology in 1909 to honor his life's work in surgery and research of thyroid pathologies. Charles Mayo began operating with his brother William in 1888 at the Mayo Clinic in Rochester, Minnesota, where subsequently a large volume of thyroid surgery was performed. George Crile in Cleveland and Frank Lahey in Boston also performed large volumes of thyroid surgery and perfected the basic techniques. Thyroid surgery is currently performed at all institutions of the mentioned pioneers, in departments of both general surgery and of otorhinolaryngology head and neck surgery.

\section{HEAD AND NECK SURGEON AND THE THYROID GLAND}

The head and neck surgeon is confronted with the thyroid and parathyroid glands and the laryngeal nerves on a daily basis. The surgical treatment of several hypopharyngeal or subglottic carcinomas include at least a hemithyroidectomy and, in selected cases, a total thyroidectomy. In partial pharyngolaryngectomies and partial laryngectomies, such as hemilaryngectomies or cricohyoidopexies, the recurrent as well as the superior laryngeal nerves must be identified and spared, to guarantee vocal cord function minimizing aspiration. Similarly, surgery of the thyroid, the central compartment of the neck, and the superior mediastinum requires equal exposure and expertise in identification and preservation of recurrent laryngeal nerves. In selected cases, the thyroid gland may even be used for the reconstruction of laryngeal defects $[16,17]$. In rare cases, differentiated thyroid carcinomas invade laryngeal structures or the trachea and require appropriate pre-operative assessment and surgical management $[18,19]$.

\section{NECK DISSECTION IN THYROID CARCINOMA}

Cervical lymph node metastases are common in differentiated thyroid carcinomas, such as papillary thyroid cancer. Depending on the diagnostic modalities employed, $30-80 \%$ of papillary thyroid carcinomas harbor lymph node metastases [20-22]. The most frequently cited types of neck dissection in relation to thyroid cancer are central and lateral neck dissection.

Central neck dissection involves the removal of nodes of the prelaryngeal, pretracheal (level VI) and paratracheal lymph node basins (level VII) [6]. Lateral neck dissection involves the removal of the upper jugular nodes (level II)except the nodes above and behind the accessory nerve (sublevel IIB) - the mid-jugular and lower jugular nodes (levels III, IV), and the posterior triangle (sublevel VB) [23].

Goyal et al. [24] analyzed a series of 416 papillary thyroid carcinomas: of 319 initial 
surgery cases, $113(35 \%)$ presented with $\mathrm{cN}+$. Overall, in $73 \%$ and $65 \%$ of patients with node metastases, these were located in the central neck dissection and lateral neck dissection specimens, respectively.

According to Weber et al. [25], the number of resected nodes in the paratracheal region ranges from 3 to 30. In a central neck dissection specimen, an average of 8.4 nodes are found on pathologic examination [26].

Eskander et al. [27] performed a review and meta-analysis on the patterns of spread to the lateral neck in metastatic well-differentiated thyroid cancers. The study inclusion criteria were: well-differentiated thyroid carcinoma with lateral neck disease treated by neck dissection (levels II-IV or II-V). Of 94 screened articles, only 18 met criteria and had sufficient data (such as disease description by level) for inclusion in the meta-analysis, and 13 of these 18 studies were performed by head neck surgeons of ORL departments. The 18 articles included 1145 patients with 1298 neck dissections. Level II was involved in 53.4\%, levels III and IV in $70.55 \%$ and $66.3 \%$, respectively, and level $\mathrm{V}$ in $25.3 \%$ of the cases.

The authors concluded that patients with lateral neck disease from papillary thyroid carcinomas should undergo a neck dissection of levels IIa, IIb, III, IV and Vb. Agrawal et al. stated that "focal berry picking of only clinically involved lymph nodes without a compartmental dissection leads to higher rates of recurrences and should be abandoned" [28]. The surgical treatment of the neck is challenging. Head and neck surgeons, dealing with head and neck carcinomas, routinely perform neck dissections and master every type of neck dissection. Unfortunately, regional recurrences of squamous cell carcinomas of the upper aerodigestive tract after irradiation or previous neck dissection are not rare. Thus, head and neck surgeons are also experienced with revision neck surgery.

\section{CONCLUSIONS}

A well-trained head and neck surgeon will have experience in treating all forms of malignancies of the head and neck, and will be familiar with vocal cord evaluation, with all types of neck dissections and with the management of the larynx and trachea. Local or regional recurrences of differentiated thyroid carcinomas are difficult to manage; the head and neck surgeon is accustomed to performing surgery in postsurgical and/or post-irradiated necks.

Expertise should not be defined by specialty but focused on facts such as experience in surgery of the neck, of post-surgical and post-irradiated necks, of neighboring structures and in the diagnosis and surgery of complications such as recurrent laryngeal nerve paralysis. Such expertise can only be maintained with a large enough volume of thyroid and neck surgeries after the training period. Thus, the question of who is qualified to perform thyroid surgery is not determined by the basic specialty certification of the surgeon, whether general surgery or otolaryngology; rather, it depends on the training, skill and surgical experience of the individual surgeon.

\section{ACKNOWLEDGEMENTS}

Funding. No funding or sponsorship was received for this study or publication of this article.

Authorship. All named authors meet the International Committee of Medical Journal Editors (ICMJE) criteria for this article, take responsibility for the integrity of the work as a whole, and have given their approval for this version to be published.

Authorship Contributions. This paper was written by members and invitees of the International Head and Neck Scientific Group (http://www.IHNSG.com). Peter Zbären prepared the manuscript. All other authors contributed equally in reviewing, amending and correcting the manuscript.

Disclosures. No named author (Peter Zbären, Jatin P. Shah, Gregory W. Randolph, Carl E. Silver, Kerry D. Olsen, Ashok R. Shaha, Mark Zafereo, Luiz P. Kowalski, Carlos Suarez, Alvaro 
Sanabria, Vincent Vander Poorten, Iain Nixon, Alessandra Rinaldo, Alfio Ferlito) has anything to disclose.

Compliance with Ethics Guidelines. This article is based on previously conducted studies and does not contain any studies with human participants or animals performed by any of the authors.

Peer Review. Please note, contrary to the journal's standard single-blind peer-review process, as an editorial this article underwent review by a member of the journal's Editorial Board.

Open Access. This article is distributed under the terms of the Creative Commons Attribution-NonCommercial 4.0 International License (http://creativecommons.org/licenses/ by-nc/4.0/), which permits any noncommercial use, distribution, and reproduction in any medium, provided you give appropriate credit to the original author(s) and the source, provide a link to the Creative Commons license, and indicate if changes were made.

\section{REFERENCES}

1. Harness JK. Presidential address: interdisciplinary care-the future of endocrine surgery. Surgery. 2000. https://doi.org/10.1067/msy.2000.110849.

2. Shaha AR. Transforming head and neck surgeon into thyroid expert the 2016 hayes martin lecture. JAMA Otolaryngol Head Neck Surg. 2016. https:// doi.org/10.1001/jamaoto.2016.3620.

3. Fundakowski CE, Hales NW, Agrawal N, Barczyński M, Camacho PM, Hartl DM, et al. Surgical management of the recurrent laryngeal nerve in thyroidectomy: American Head and Neck Society Consensus Statement. Head Neck. 2018. https:// doi.org/10.1002/hed.24928.

4. Randolph GW, Duh Q-Y, Heller KS, LiVolsi VA, Mandel SJ, Steward DL, et al. The prognostic significance of nodal metastases from papillary thyroid carcinoma can be stratified based on the size and number of metastatic lymph nodes, as well as the presence of extranodal extension. Thyroid. 2012. https://doi.org/10.1089/thy.2012.0043.
5. Urken ML, Milas M, Randolph GW, Tufano R, Bergman D, Bernet V, et al. Management of recurrent and persistent metastatic lymph nodes in welldifferentiated thyroid cancer: a multifactorial decision-making guide for the thyroid cancer care collaborative. Head Neck. 2015. https://doi.org/10. 1002/hed.23615.

6. Carty SE, Cooper DS, Doherty GM, Duh QY, Kloos RT, Mandel SJ, et al. Consensus statement on the terminology and classification of central neck dissection for thyroid cancer: the American thyroid association surgery working group with participation from the American association of endocrine surgeons, American academy of otolaryngologyhead and neck surgery, and American head and neck society. Thyroid. 2009;19(11):1153-8.

7. Haugen BR, Alexander EK, Bible KC, Doherty GM, Mandel SJ, Nikiforov YE, et al. 2015 American Thyroid Association Management Guidelines for adult patients with thyroid nodules and differentiated thyroid cancer. Thyroid. 2016;26:1-133.

8. Gonçalves FJ, Zafereo ME, Ahmad FI, Nixon IJ, Shaha AR, Vander Poorten V, et al. Decision making for the central compartment in differentiated thyroid cancer. Eur J Surg Oncol. 2018. https://doi.org/ 10.1016/j.ejso.2018.08.005.

9. Czerwonka L, Freeman J, McIver B, Randolph GW, Shah JP, Shaha AR, et al. Summary of proceedings of the second World Congress on Thyroid Cancer. Head Neck. 2014. https://doi.org/10.1002/hed. 23631.

10. McIver B, Freeman J, Shah JP, Shaha AR, Haugen B, Cohen E, et al. Summary of the Third World Congress on thyroid cancer. Thyroid. 2018. https://doi. org/10.1089/thy.2018.0616.

11. Bevan PG. Generalism and specialisation in surgery. Ann R Coll Surg Engl. 1981;63(6):383.

12. Bruns SD, Davis BR, Demirjian AN, Ganai S, House MG, Saidi RF, et al. The subspecialization of surgery: a Paradigm Shift. J Gastrointest Surg. 2014. https:// doi.org/10.1007/s11605-014-2514-4.

13. Shah JP. Head and neck surgery in crisis. Arch Otolaryngol Neck Surg. 2005. https://doi.org/10. 1001/archotol.131.7.556.

14. Becker WF. Presidential address: pioneers in thyroid surgery. Ann Surg. 1977;185:493.

15. Hannan SA. The magnificent seven: a history of modern thyroid surgery. Int J Surg. 2006. https:// doi.org/10.1016/j.ijsu.2006.03.002.

16. Ikeda A, Okamoto H, Tsuchiya $\mathrm{Y}$, Nishimura K, Ueda $H$, Ogawa $T$. Case of partial vertical 
laryngectomy with vocal cord reconstruction using a thyroid gland flap. Head Neck. 2014. https://doi. org/10.1002/hed.23525.

17. Kojima H, Omori K, Fujita A, Nonomura M. Thyroid gland flap for glottic reconstruction after vertical laryngectomy. Am J Otolaryngol Neck Med Surg. $1990 . \quad$ https://doi.org/10.1016/01960709(90)90063-2.

18. Zbären P, Nuyens M, Thoeny HC, Stauffer E. Laryngeal involvement by differentiated thyroid carcinoma. Am J Surg. 2005. https://doi.org/10. 1016/j.amjsurg.2005.04.009.

19. Nixon IJ, Simo R, Newbold K, Rinaldo A, Suarez C, Kowalski LP, et al. Management of invasive differentiated thyroid cancer. Thyroid. 2016. https://doi. org/10.1089/thy.2016.0064.

20. Nixon IJ, Shaha AR. Management of regional nodes in thyroid cancer. Oral Oncol. 2013. https://doi. org/10.1016/j.oraloncology.2013.03.441.

21. Vas Nunes JH, Clark JR, Gao K, Chua E, Campbell P, Niles N, et al. Prognostic implications of lymph node yield and lymph node ratio in papillary thyroid carcinoma. Thyroid. 2013. https://doi.org/10. 1089/thy.2012.0460.

22. Ducoudray R, Trésallet C, Godiris-Petit G, Tissier F, Leenhardt L, Menegaux F. Prophylactic lymph node dissection in papillary thyroid carcinoma: is there a place for lateral neck dissection? World J Surg. 2013. https://doi.org/10.1007/s00268-013-2020-y.

23. Stack BC, Ferris RL, Goldenberg D, Haymart M, Shaha A, Sheth S, et al. American Thyroid
Association consensus review and statement regarding the anatomy, terminology, and rationale for lateral neck dissection in differentiated thyroid cancer. Thyroid. 2012. https://doi.org/10.1089/thy. 2011.0312.

24. Goyal N, Pakdaman M, Kamani D, Caragacianu D, Goldenberg D, Randolph GW. Mapping the distribution of nodal metastases in papillary thyroid carcinoma: where exactly are the nodes? Laryngoscope. 2017. https://doi.org/10.1002/lary.26495.

25. Weber RS, Marvel J, Smith P, Hankins P, Wolf P, Goepfert H. Paratracheal lymph node dissection for carcinoma of the larynx, hypopharynx, and cervical esophagus. Otolaryngol Neck Surg. 1993. https://doi.org/10.1177/019459989310800102.

26. Pereira JA, Jimeno J, Miquel J, Iglesias M, Munné A, Sancho JJ, et al. Nodal yield, morbidity, and recurrence after central neck dissection for papillary thyroid carcinoma. Surgery. 2005. https://doi.org/ 10.1016/j.surg.2005.09.013.

27. Eskander A, Merdad M, Freeman JL, Witterick IJ. Pattern of spread to the lateral neck in metastatic well-differentiated thyroid cancer: a systematic review and meta-analysis. Thyroid. 2012. https:// doi.org/10.1089/thy.2012.0493.

28. Agrawal N, Evasovich MR, Kandil E, Noureldine SI, Felger EA, Tufano RP, et al. Indications and extent of central neck dissection for papillary thyroid cancer: an American Head and Neck Society Consensus Statement. Head Neck. 2017. https://doi.org/ 10.1002/hed.24715. 